\title{
Cornea-PAMPA as an Orthogonal in Vitro Physicochemical Model of Corneal Permeability
}

\author{
Anna Vincze1, Gergő Dargó1, György Tibor Balogh ${ }^{1,2^{*}}$ \\ 1 Department of Chemical and Environmental Process Engineering, Faculty of Chemical Technology and Biotechnology, Budapest \\ University of Technology and Economics, H-1111 Budapest, Múegyetem rakpart 3., Hungary \\ 2 Institute of Pharmacodynamics and Biopharmacy, Faculty of Pharmacy, University of Szeged, H-6720 Szeged, Zrínyi u. 9., \\ Hungary \\ * Corresponding author, e-mail: gytbalogh@mail.bme.hu
}

Received: 21 January 2020, Accepted: 17 March 2020, Published online: 25 May 2020

\begin{abstract}
The present study was aimed to investigate the relationships between permeability and membrane retention values (log $P_{e}$ and $M R$ ) of the in vitro non-cellular permeability assay, corneal-PAMPA in comparison with experimental Caco-2 permeability data and calculated physicochemical properties (MW, $\left.\operatorname{cog} P, \operatorname{cog} D_{7.4}, \mathrm{TPSA}\right)$. For the investigation, 50 structurally and physicochemically diverse drugs were selected and measured in PAMPA model optimized for corneal permeability. The results showed corneal-PAMPA model's orthogonality in terms of passive diffusion to the FDA approved Caco-2 as a gastrointestinal absorption model, while the comparison with physicochemical properties revealed trends between $\log P_{e}, \mathrm{MR}$ and the lipophilicity descriptors and TPSA.
\end{abstract}

Keywords

corneal-PAMPA, permeability, membrane retention, physicochemical descriptors, clogP/D ${ }_{7.4}$, TPSA

\section{Introduction}

The effective treatment of diseases affecting the human eye is of utmost importance as they might cause partial visual impairment or even complete blindness [1]. For the treatment of the anterior segment of the eye, topical drug administration is the preferred way of therapy. To this avail, eye drops, ophthalmic solutions, eye ointments and gels, microemulsions, drug-eluting contact lenses, ocular inserts, liposomes, nano- and microparticles etc. can be used [2-4]. However, ocular bioavailability of these topically administered drugs is limited by several factors: lacrimal fluid rapidly elutes a large portion of the applied drugs within a few minutes upon administration [5]; the drug fraction absorbed through non-corneal routes is mostly transferred into the systematic circulation [6]. These result in a decreased bioavailability (usually $<5-10 \%$ ) [7, 8], while the therapeutic effect can mainly be attributed to the drug fraction absorbed via the corneal route [6]. The human cornea is a unique and complex biological barrier which consists of five distinct layers: the epithelium, Bowman's layer, the stroma, Descemet's membrane, and the endothelium $[6,9,10]$. For the absorption of the drug into the aqueous humor it has to penetrate through these layers of hydrophilic and lipophilic character, however, it has been reported that in the case of most drugs the epithelial layer is the rate-limiting barrier [11, 12] which is responsible for about $99 \%$ of the resistance to the diffusion of APIs through the cornea [13].

To predict the corneal permeability of APIs, several methods exist: ex vivo models using the eyes or excised cornea of vertebrate animals (most often rabbit, pig or bovine eyes) [10], while to minimize the number of laboratory animals sacrificed and to limit the cost of ex vivo studies, in vitro cellular models using primary cell cultures, immortalized cell lines, or reconstructed tissue cultures of rabbit or human origin $[10,14]$ are used and recently an in vitro non-cellular method, corneal-PAMPA has also been developed by our group to this avail [15].

The corneal-PAMPA method has been developed based on ex vivo rabbit corneal permeability data $[7,12]$ using the parallel artificial membrane permeability assay (PAMPA) [16]. Based on previous experience with the PAMPA model [17, 18], we investigated the effects of the composition of the artificial lipid membrane, the DMSO cosolvent content of the donor phase as well as different 
buffer solutions in the model. We found that the best correlation $\left(R^{2}=0.880\right)$ with the ex vivo data could be achieved using the following optimized conditions: iso-pH conditions using phosphate buffer saline (PBS, $\mathrm{pH}$ 7.4) without cosolvent, phosphatidylcholine $(\mathrm{PC}=10.7 \%(\mathrm{w} / \mathrm{v})$; without cholesterol) dissolved in a solvent mixture of hexane:dodecane:chloroform $=70: 25: 5(\mathrm{v} / \mathrm{v})$ as an artificial membrane and a 4 hour long incubation of the PAMPA plates at $35^{\circ} \mathrm{C}$.

In this study, we have investigated the orthogonality between corneal-PAMPA and the FDA approved industrial cellular permeability standard, Caco-2 based on experimental data. We also aimed to investigate the extent of correlation between the experimentally determined corneal-PAMPA data (permeability $\left(\log P_{e}\right)$ and membrane retention (MR)) and basic physicochemical properties (MW and in silico predicted $\operatorname{cog} P, \operatorname{clog} D_{7.4}$, TPSA) to determine if it is possible to predict corneal permeability values based on these basic descriptors.

\section{Experimental}

\subsection{Materials}

Analytical grade solvents such as acetonitrile (MeCN), chloroform, dodecane, hexane and formic acid were purchased from Merck KGaA (Darmstadt, Germany). Phosphate buffered saline (PBS) powder, L- $\alpha$ phosphatidylcholine (PC) and the reference materials (aldosterone, amitriptyline hydrochloride, antipyrine, atenolol, atropine sulfate, bupropion hydrochloride, carbamazepine, chloramphenicol, chlorpromazine hydrochloride, cimetidine hydrochloride, ciprofloxacin, clonidine, desipramine hydrochloride, diazepam, diclofenac sodium, diflunisal, diltiazem hydrochloride, ephedrine hydrochloride, etoposide, famotidine, furosemide, haloperidol, hydrocortisone, ibuprofen, imipramine hydrochloride, irbesartan, ketoprofen, labetalol hydrochloride, lidocaine, loperamide hydrochloride, meloxicam sodium, metoprolol, nadolol, naproxen, ofloxacin, phenytoin, pindolol, pirenzepine 2 hydrochloride, piroxicam, prazosin hydrochloride, prednisolone, propranolol hydrochloride, quinine, sparfloxacin, theophylline, trimethoprim, verapamil hydrochloride, warfarin) were purchased from Sigma Aldrich Co. Ltd. (Budapest, Hungary). Further reference materials (betaxolol hydrochloride, flurbiprofen) were purchased from Toronto Research Chemicals Inc. (North York, Toronto, Canada). In all experiments, distilled water was purified by the Millipore Milli-Q ${ }^{\circledR} 140$ Gradient Water Purification System.

\subsection{Corneal-PAMPA measurements}

For in vitro transcorneal permeability measurement the previously reported cornea-PAMPA method was used [15]. Briefly the drugs were dissolved in PBS buffer ( $\mathrm{pH} 7.4$ ) to make solutions of $100 \mu \mathrm{M}$ nominal concentration. Before each assay the PBS solutions were homogenized by using an Eppendorf MixMate vortex mixer for 10-12 s and by an ultrasonic bath (Bandelin Sonorex Digiplus) for $10 \mathrm{~min}$. For creation of the lipid membrane phosphatidylcholine (PC, $16 \mathrm{mg}$ ) was dissolved in a solvent mixture (70 \% (v/v) hexane, $25 \%$ (v/v) dodecane, $5 \%$ (v/v) chloroform) and then each well of donor plate (MultiscreenTM-IP, MAIPN4510, pore size $0.45 \mathrm{~mm}$; Millipore) was coated with the lipid solution ( $5 \mu \mathrm{L}$ each). Then the hexane and chloroform were evaporated to form a PC lipid membrane with the concentration of $10.67 \mathrm{w} / \mathrm{v} \%$ in each well. Then the donor plate was fit into the acceptor plate (Multiscreen Acceptor Plate, MSSACCEPTOR; Millipore) containing $300 \mu \mathrm{L}$ of PBS solution ( $\mathrm{pH} 7.4$ ), and $150-150 \mu \mathrm{L}$ of the PBS solutions were put on the membrane of the donor plate. The donor plate was covered with a sheet of wet tissue paper and a plate lid to avoid evaporation. The plates were incubated for $4 \mathrm{~h}$ at $35{ }^{\circ} \mathrm{C}$ (Heidolph Titramax 1000) followed by separation of PAMPA sandwich plates and determination of concentrations of the APIs in the donor and acceptor solutions by HPLC-DAD. The concentration of donor solutions at time point zero was also determined using the same HPLC system. Test solutions from PAMPA experiments were prepared in 96-well plates and sealed before injection. For each assay 3 replicates per compounds were measured.

The effective permeability and membrane retention of drugs were calculated using Eq. (1) [16]:

$$
P_{e}=\frac{-2.303}{A \times\left(t-\tau_{s s}\right)} \times\left(\frac{1}{1+r_{v}}\right) \times \lg \left[-r_{v}+\left(\frac{1+r_{v}}{1-\mathrm{MR}}\right) \times \frac{C_{D}(t)}{C_{D}(0)}\right],
$$

where $P_{e}$ is the effective permeability coefficient $(\mathrm{cm} / \mathrm{s})$, $A$ is the filter area $\left(0.3 \mathrm{~cm}^{2}\right), t$ is the incubation time (s), $\tau_{s s}$ is the time to reach steady-state (s), $r_{v}$ is the volume ratio of aqueous compartments $\left(V_{D} / V_{A}\right), V_{D}$ and $V_{A}$ are the volumes in the donor $\left(0.15 \mathrm{~cm}^{3}\right)$ and acceptor phase $\left(0.3 \mathrm{~cm}^{3}\right), c_{D}(t)$ is the concentration of the compound in the donor phase at time point $t\left(\mathrm{~mol} / \mathrm{cm}^{3}\right), c_{D}(0)$ is the concentration of the compound in the donor phase at time point zero $\left(\mathrm{mol} / \mathrm{cm}^{3}\right)$ and $\mathrm{MR}$ is the membrane retention factor, defined as [16]:

$$
\mathrm{MR}=1-\frac{C_{D}(t)}{C_{D}(0)}-\frac{V_{A} \times C_{A}(t)}{V_{D} \times C_{D}(t)}
$$


where $c_{A}(t)$ is the concentration of the compound in the acceptor phase at time point $t\left(\mathrm{~mol} / \mathrm{cm}^{3}\right)$.

\subsection{HPLC-methods}

Quantitative chromatographic analyses were performed using an Agilent 1260 liquid chromatography system equipped with a vacuum degasser, a quaternary pump, a thermostatted autosampler, a column temperature controller and a diode array detector (Agilent Technologies, Palo Alto, CA, USA) at $45{ }^{\circ} \mathrm{C}$ on a Kinetex ${ }^{\circledR} 2.6 \mu \mathrm{m} \mathrm{C18}$ $100 \AA$ LC column $(30 \times 3 \mathrm{~mm})$ with a mobile phase flow rate of $1.1 \mathrm{~mL} / \mathrm{min}$. Composition of mobile phase A was $0.1 \%(\mathrm{v} / \mathrm{v})$ formic acid in water, $\mathrm{B}$ was $\mathrm{MeCN} /$ water $95 / 5(\mathrm{v} / \mathrm{v})$ with $0.1 \%(\mathrm{v} / \mathrm{v})$ of formic acid. A $3.91 \mathrm{~min}$ long, linear gradient program was applied: $0 \% \mathrm{~B}$ in the first $0.3 \mathrm{~min}, 0-100 \% \mathrm{~B}$ between 0.3 and $1.8 \mathrm{~min}$, then $100 \%$ $\mathrm{B}$ was kept for another $0.6 \mathrm{~min}$, and finally at $2.41 \mathrm{~min}$ the percentage of $\mathrm{B}$ was dropped to $0 \%$. This was followed by an equilibration period of $1.5 \mathrm{~min}$ prior to the next injection. Chromatograms were recorded at the wavelength of 200-500 nm, integration was carried out at the $\mathrm{UV}_{\max }$ of each compound. The applied injection volume was $6 \mu \mathrm{L}$. ChemStation B.04.03 was used for data acquisition and analysis.

\section{Results and discussion}

For our experiments, we have selected fifty APIs of commercially available drugs (Table 1) with diverse molecular structure and physicochemical parameters covering a broad range of molecular weight $(\mathrm{MW}=165-589)$, lipophilicity descriptors $\left(\operatorname{cog} P=-2.0-5.4, \operatorname{cog} D_{7.4}=-2.7-4.2\right)$ and topological polar surface area (TPSA $=3-176 \AA^{2}$ ). Table 1 also contains the in vitro corneal permeability and membrane retention values measured by the corneal-PAMPA method [15], as well as previously reported experimental Caco-2 permeability data [19-21].

As we can see in Fig. 1 only a weak correlation could be observed between the in vitro experimental corneal-PAMPA and Caco-2 permeability values (Pearson correlation coefficient, $r=0.354$ ), which indicates that our model is independent of this generally accepted gastrointestinal permeability model and supports its adequacy for cornea-specific in vitro measurements.

To investigate the correlation of corneal permeability values and basic physicochemical parameters $\operatorname{cog} P$, $\operatorname{cog} D_{7.4}$ and TPSA values have been predicted using the Marvin calculator plugin [22] (Table 1). Determination of correlation coefficients and model fitting was carried out using GraphPad Prism v.7.03. [23].

Table 1 In silico predicted physicochemical parameters and experimental corneal-PAMPA and Caco-2 permeability values of investigated APIs

\begin{tabular}{|c|c|c|c|c|c|c|c|c|c|c|c|c|c|}
\hline \multirow[b]{2}{*}{ API name } & \multirow[b]{2}{*}{ MW } & \multirow[b]{2}{*}{$\operatorname{clog} P^{*}$} & \multirow[b]{2}{*}{$\operatorname{clog} D_{7.4}{ }^{*}$} & \multirow{2}{*}{$\begin{array}{c}\mathrm{TPSA}^{*} \\
\left(\AA^{2}\right)\end{array}$} & \multicolumn{6}{|c|}{ Corneal-PAMPA } & \multicolumn{3}{|c|}{ Caco-2 } \\
\hline & & & & & $\begin{array}{c}P_{e} \\
\left(10^{-6} \mathrm{~cm} / \mathrm{s}\right)\end{array}$ & SD & $\log P_{e}$ & SD & MR & SD & $\begin{array}{c}P_{e} \\
\left(10^{-6} \mathrm{~cm} / \mathrm{s}\right)\end{array}$ & $\log P_{e}$ & Ref. \\
\hline aldosterone & 360.45 & 1.06 & 1.06 & 91.67 & 9.05 & 0.12 & -5.04 & 0.01 & 4.06 & 1.65 & 48.98 & -4.31 & [19] \\
\hline amitriptyline & 277.41 & 4.81 & 2.48 & 3.24 & 24.52 & 2.43 & -4.61 & 0.04 & 73.36 & 1.04 & 20.89 & -4.68 & [19] \\
\hline antipyrine & 188.23 & 1.22 & 1.22 & 23.55 & 15.46 & 2.15 & -4.81 & 0.06 & 1.50 & 0.40 & 28.18 & -4.55 & {$[20]$} \\
\hline atenolol & 266.34 & 0.43 & -1.80 & 84.58 & 0.00 & - & - & - & 2.58 & 0.44 & 0.36 & -6.44 & {$[20]$} \\
\hline atropine & 289.38 & 1.57 & -0.41 & 49.77 & 6.81 & 1.97 & -5.18 & 0.13 & 3.93 & 0.36 & 19.50 & -4.71 & [19] \\
\hline betaxolol & 307.43 & 2.54 & 0.31 & 50.72 & 23.67 & 2.82 & -4.63 & 0.05 & 10.31 & 2.17 & 30.20 & -4.52 & {$[20]$} \\
\hline bupropion & 239.74 & 3.27 & 2.39 & 29.10 & 32.65 & 0.30 & -4.47 & 0.05 & 34.44 & 2.38 & 151.36 & -3.82 & {$[21]$} \\
\hline carbamazepine & 236.27 & 2.77 & 2.77 & 46.33 & 29.68 & 3.15 & -4.53 & 0.05 & 8.26 & 1.91 & 5.01 & -5.30 & {$[21]$} \\
\hline chloramphenicol & 323.13 & 0.88 & 0.86 & 112.70 & 2.53 & 0.08 & -5.60 & 0.01 & 8.40 & 0.61 & 20.42 & -4.69 & {$[20]$} \\
\hline chlorpromazine & 318.86 & 4.54 & 2.74 & 6.48 & 6.73 & 2.31 & -5.19 & 0.15 & 86.24 & 0.98 & 19.95 & -4.70 & {$[20]$} \\
\hline cimetidine & 252.34 & -0.11 & -0.22 & 88.89 & 0.00 & - & - & - & 1.50 & 1.29 & 1.29 & -5.89 & {$[20]$} \\
\hline ciprofloxacin & 331.35 & -0.86 & -0.87 & 72.88 & 0.25 & 0.19 & -6.70 & 0.28 & 4.21 & 1.36 & 2.95 & -5.53 & {$[21]$} \\
\hline clonidine & 230.09 & 2.49 & 1.66 & 36.42 & 24.05 & 2.40 & -4.62 & 0.04 & 6.91 & 4.97 & 25.70 & -4.59 & {$[20]$} \\
\hline desipramine & 266.39 & 3.90 & 1.37 & 15.27 & 54.42 & 1.33 & -4.26 & 0.01 & 27.46 & 3.05 & 21.38 & -4.67 & {$[20]$} \\
\hline diazepam & 284.74 & 3.08 & 3.08 & 32.67 & 60.28 & 2.70 & -4.22 & 0.02 & 38.90 & 3.86 & 47.86 & -4.32 & [20] \\
\hline diclofenac & 296.15 & 4.26 & 1.10 & 49.33 & 19.96 & 2.63 & -4.70 & 0.06 & 8.33 & 1.81 & 53.70 & -4.27 & {$[21]$} \\
\hline diflunisal & 250.2 & 3.91 & 0.41 & 57.53 & 5.84 & 0.36 & -5.23 & 0.03 & 14.29 & 0.79 & 12.59 & -4.90 & [19] \\
\hline diltiazem & 414.52 & 2.73 & 1.89 & 59.08 & 44.73 & 0.40 & -4.35 & 0.00 & 28.49 & 4.44 & 41.69 & -4.38 & [20] \\
\hline ephedrine & 165.24 & 1.32 & -0.78 & 32.26 & 12.18 & 1.26 & -4.92 & 0.05 & 8.85 & 0.51 & 10.23 & -4.99 & [19] \\
\hline etoposide & 588.56 & 1.16 & 1.16 & 160.83 & 0.73 & 0.09 & -6.14 & 0.05 & 8.38 & 1.74 & 1.00 & -6.00 & [21] \\
\hline
\end{tabular}




\begin{tabular}{|c|c|c|c|c|c|c|c|c|c|c|c|c|c|}
\hline \multirow[b]{2}{*}{ API name } & \multirow[b]{2}{*}{ MW } & \multirow[b]{2}{*}{$\operatorname{clog} P^{*}$} & \multirow[b]{2}{*}{$\operatorname{clog} D_{7.4}{ }^{*}$} & \multirow[b]{2}{*}{$\begin{array}{c}\text { TPSA }^{*} \\
\left(\AA^{2}\right)\end{array}$} & \multicolumn{6}{|c|}{ Corneal-PAMPA } & \multicolumn{3}{|c|}{ Caco-2 } \\
\hline & & & & & $\begin{array}{c}P_{e} \\
\left(10^{-6} \mathrm{~cm} / \mathrm{s}\right)\end{array}$ & SD & $\log P_{e}$ & $\mathrm{SD}$ & MR & SD & $\begin{array}{c}P_{e} \\
\left(10^{-6} \mathrm{~cm} / \mathrm{s}\right)\end{array}$ & $\log P_{e}$ & Ref. \\
\hline famotidine & 337.44 & -1.95 & -2.67 & 175.83 & 0.38 & 0.31 & -6.55 & 0.42 & 1.11 & 0.68 & 0.89 & -6.05 & [19] \\
\hline flurbiprofen & 244.27 & 3.94 & 1.07 & 37.30 & 16.47 & 1.77 & -4.79 & 0.05 & 1.94 & 2.34 & 33.88 & -4.47 & [21] \\
\hline furosemide & 330.74 & 1.75 & -1.25 & 122.63 & 1.07 & 0.80 & -6.10 & 0.45 & 0.56 & 2.07 & 0.31 & -6.51 & {$[20]$} \\
\hline haloperidol & 375.87 & 3.66 & 2.93 & 40.54 & 40.66 & 6.60 & -4.40 & 0.07 & 41.16 & 9.67 & 15.85 & -4.80 & [21] \\
\hline hydrocortisone & 362.47 & 1.28 & 1.28 & 94.83 & 5.58 & 1.96 & -5.28 & 0.17 & 10.80 & 3.08 & 21.88 & -4.66 & [20] \\
\hline ibuprofen & 206.29 & 3.84 & 1.34 & 37.30 & 21.90 & 2.75 & -4.66 & 0.06 & 1.26 & 2.20 & 52.48 & -4.28 & [20] \\
\hline imipramine & 280.42 & 4.28 & 2.48 & 6.48 & 15.59 & 0.30 & -4.61 & 0.26 & 50.34 & 4.51 & 14.13 & -4.85 & {$[20]$} \\
\hline irbesartan & 428.54 & 5.39 & 4.23 & 87.13 & 2.23 & 0.51 & -5.66 & 0.10 & 8.55 & 1.36 & 11.75 & -4.93 & [19] \\
\hline ketoprofen & 254.29 & 3.61 & 0.39 & 54.37 & 8.36 & 0.57 & -5.08 & 0.03 & 0.00 & 1.06 & 46.77 & -4.33 & [21] \\
\hline labetalol & 328.41 & 1.89 & 1.26 & 95.58 & 3.78 & 0.72 & -5.43 & 0.09 & 18.73 & 2.55 & 9.33 & -5.03 & [20] \\
\hline lidocaine & 234.34 & 2.84 & 2.33 & 32.34 & 61.68 & 1.07 & -4.21 & 0.01 & 7.07 & 1.25 & 61.66 & -4.21 & [20] \\
\hline loperamide & 477.05 & 4.77 & 2.77 & 43.78 & 37.76 & 3.77 & -4.42 & 0.04 & 37.23 & 1.59 & 20.89 & -4.68 & [19] \\
\hline meloxicam & 351.4 & 1.60 & -1.10 & 99.60 & 6.99 & 0.57 & -5.16 & 0.03 & 4.22 & 2.24 & 19.50 & -4.71 & [20] \\
\hline metoprolol & 267.37 & 1.76 & -0.47 & 50.72 & 14.19 & 1.22 & -4.85 & 0.04 & 2.95 & 1.75 & 25.70 & -4.59 & [20] \\
\hline nadolol & 309.41 & 0.87 & -1.44 & 81.95 & 0.00 & - & - & - & 4.12 & 0.87 & 3.89 & -5.41 & [20] \\
\hline naproxen & 230.26 & 2.99 & -0.05 & 46.53 & 11.51 & 1.04 & -4.94 & 0.04 & 0.00 & 0.31 & 14.79 & -4.83 & [20] \\
\hline ofloxacin & 361.37 & 0.09 & -0.51 & 73.32 & 1.56 & 0.54 & -5.83 & 0.14 & 3.77 & 1.13 & 21.38 & -4.67 & [19] \\
\hline phenytoin & 252.27 & 2.15 & 2.11 & 58.20 & 19.05 & 1.21 & -4.72 & 0.03 & 20.14 & 2.25 & 26.92 & -4.57 & [20] \\
\hline pindolol & 248.33 & 1.69 & -0.53 & 57.28 & 9.05 & 1.51 & -5.05 & 0.08 & 2.90 & 1.64 & 16.60 & -4.78 & [20] \\
\hline pirenzepine & 351.41 & 0.97 & 0.76 & 68.78 & 0.34 & 0.27 & -6.55 & 0.33 & 9.62 & 1.72 & 0.44 & -6.36 & [20] \\
\hline piroxicam & 331.35 & 0.60 & -1.52 & 99.60 & 14.11 & 1.70 & -4.85 & 0.05 & 3.95 & 1.57 & 35.48 & -4.45 & [20] \\
\hline prazosin & 383.41 & 1.65 & 1.43 & 106.95 & 7.85 & 3.20 & -5.13 & 0.18 & 40.35 & 6.19 & 43.65 & -4.36 & [20] \\
\hline prednisolone & 360.45 & 1.27 & 1.27 & 94.83 & 3.50 & 0.66 & -5.46 & 0.08 & 11.57 & 2.46 & 20.42 & -4.69 & [19] \\
\hline propranolol & 259.35 & 2.58 & 0.36 & 41.49 & 37.05 & 2.57 & -4.43 & 0.03 & 21.50 & 1.36 & 26.30 & -4.58 & [20] \\
\hline quinine & 324.42 & 2.51 & 0.86 & 45.59 & 20.61 & 0.26 & -4.69 & 0.01 & 20.42 & 1.67 & 112.20 & -3.95 & [19] \\
\hline sparfloxacin & 392.41 & -0.08 & -0.08 & 98.90 & 4.86 & 1.57 & -5.33 & 0.16 & 6.95 & 1.70 & 32.36 & -4.49 & [19] \\
\hline theophylline & 180.17 & -0.77 & -0.89 & 69.30 & 4.36 & 1.31 & -5.38 & 0.15 & 1.78 & 0.34 & 44.67 & -4.35 & [20] \\
\hline trimethoprim & 290.32 & 1.28 & 1.10 & 105.51 & 6.14 & 1.78 & -5.22 & 0.12 & 6.83 & 2.05 & 87.10 & -4.06 & [21] \\
\hline verapamil & 454.61 & 5.04 & 2.79 & 63.95 & 29.00 & 4.19 & -4.80 & 0.15 & 11.56 & 21.08 & 26.30 & -4.58 & [20] \\
\hline warfarin & 308.33 & 2.74 & 0.94 & 63.60 & 12.66 & 1.83 & -4.73 & 0.23 & 23.19 & 25.42 & 13.80 & -4.86 & [20] \\
\hline
\end{tabular}

${ }^{*} \operatorname{cog} P, \operatorname{cog} D_{7.4}$ and TPSA values were predicted by the Chemaxon/Marvin Calculator plugin [22].

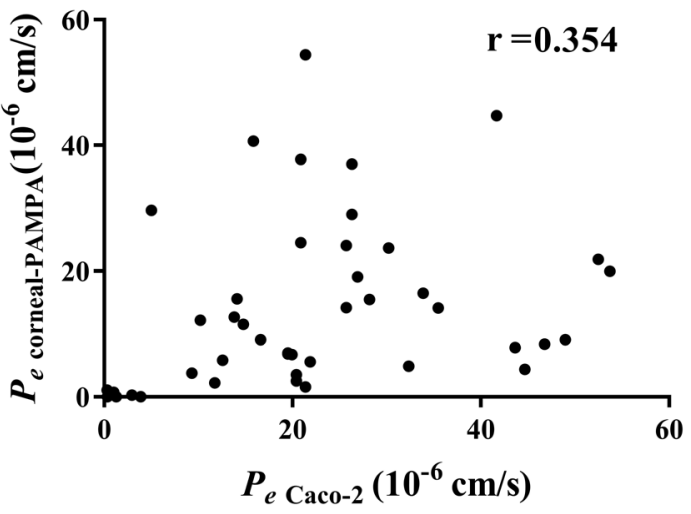

Fig. 1 Correlation between experimental corneal-PAMPA and Caco-2 permeability values, $r$ is the Pearson correlation coefficient [23].
Fig. 2 shows the relationship between the in silico parameters and permeability and membrane retention values of corneal-PAMPA. In the case of $\log P_{e}$ values, only a weak correlation could be observed with MW (Fig. 2 (A)), while the comparison revealed a moderate correlation with $\operatorname{cog} D_{7.4}$ (Fig. 2 (E)), a strong positive correlation in the case of $\operatorname{cog} P$ (Fig. $2(\mathrm{C}))$ and a strong negative correlation with TPSA (Fig. $2(\mathrm{G})$ ). These are in agreement with the fact that the more lipophilic a drug is, the easier it can partition into the membrane (PC, in our model). On the other hand, a large polar surface area will hinder that process, therefore a negative trend can be expected. However, the goodness of fit $\left(R^{2}\right)$ values of the straight 
A
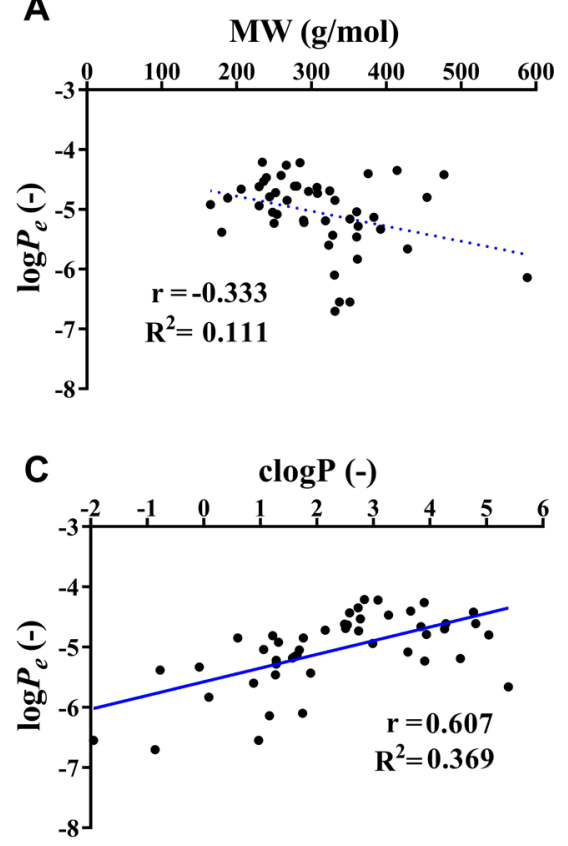

E

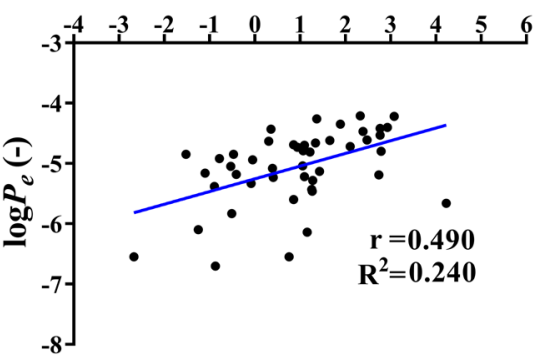

G

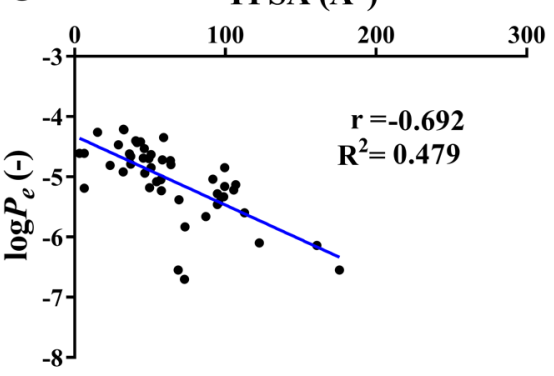

B
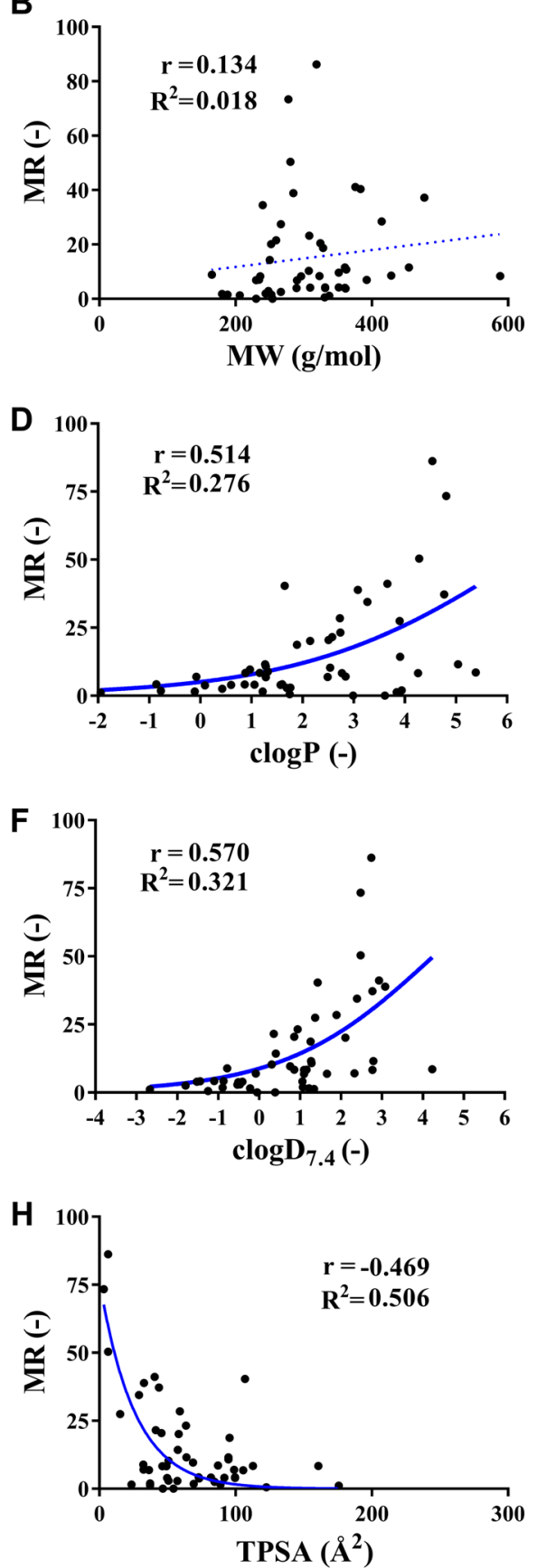

Fig. 2 Correlation between experimental corneal permeability $\left(\log P_{e}\right)$, membrane retention $(\mathrm{MR})$ and in silico predicted physicochemical parameters (clog $P$ : the logarithm of the partition coefficient, $\operatorname{cog} \mathrm{D}_{7.4}$ : the logarithm of the distribution coefficient at pH 7.4, TPSA: topological polar surface area). Physicochemical parameters were predicted by the Chemaxon/Marvin Sketch 19.19.0 plugin [22]. $r$ is the Pearson correlation coefficient, $R^{2}$ is the goodness of fit of the fitted model calculated using GraphPad Prism v. 7.03 [23].

lines fitted onto the datapoint using linear regression analysis were low, only poor fits could be achieved in all cases.

Similar observations could be made in the case of MR values: it showed a very weak correlation with MW (Fig. 2 (B)), moderately strong correlation with the lipophilicity descriptors ( $\log D_{7.4}$ and $\operatorname{cog} P$ (Figs. 2 (D) and (F)) and TPSA (Fig. $2(\mathrm{H})$ ). The relationship between MR and the lipophilicity descriptors seemed to be non-linear, instead a sigmoidal model could be fitted over the datapoints, although it showed only a poor fit. In the case of TPSA and MR a fair fit could be observed using an exponential model.

The observed relationships between $\log P_{e}$, MR and the predicted physicochemical descriptors show that using only one basic parameter separately would not result 
in precise prediction of corneal permeability. To improve the goodness of in silico prediction, a larger dataset of measured permeability values would be needed to carry out a QSPR analysis that uses further physicochemical descriptors.

\section{Conclusions}

Due to the particularly low bioavailability of ophthalmic formulations, the prediction of corneal permeability is essential from the early stage of drug discovery. To this avail a high throughput, non-cellular in vitro permeability assay, corneal-PAMPA has been developed. In the current study, we compared corneal-PAMPA permeability data of fifty APIs with experimental Caco-2 permeability values, which showed that the two models are independent of each other. We also investigated the relationship between $\log P_{e}$

\section{References}

[1] Bruce, A. S., Loughnan, M. S. "Anterior Eye Disease and Therapeutics A-Z", Churchill Livingstone, London, UK, 2011.

[2] Baranowski, P., Karolewicz, B., Gajda, M., Pluta, J. "Ophthalmic Drug Dosage Forms: Characterisation and Research Methods", The Scientific World Journal, 2014, Article ID: 861904, 2014. https://doi.org/10.1155/2014/861904

[3] Achouri, D., Alhanout, K., Piccerelle, P., Andrieu, V. "Recent advances in ocular drug delivery", Drug Development and Industrial Pharmacy, 39(11), pp. 1599-1617, 2013. https://doi.org/10.3109/03639045.2012.736515

[4] Mitra, A. K. (ed.) "Ophthalmic Drug Delivery Systems", CRC Press, Boca Raton, FL, USA, 2003. https://doi.org/10.1201/9780203912072

[5] Ahmed, I. "The Noncorneal Route in Ocular Drug Delivery", In: Mitra, A. K. (ed.) Ophthalmic Drug Delivery Systems, Marcel Dekker, New York, NY, USA, 2003, pp. 356-385. https://doi.org/10.1201/9780203912072.ch11

[6] Barar, J., Javadzadeh, A. R., Omidi, Y. "Ocular novel drug delivery: impacts of membranes and barriers", Expert Opinion on Drug Delivery, 5(5), pp. 567-581, 2008. https://doi.org/10.1517/17425247.5.5.567

[7] Kidron, H., Vellonen, K. S., del Amo, E. M., Tissari, A., Urtti, A. "Prediction of the Corneal Permeability of Drug-Like Compounds", Pharmaceutical Research, 27(7), pp. 1398-1407, 2010. https://doi.org/10.1007/s11095-010-0132-8

[8] Koevary, S. B. "Pharmacokinetics of Topical Ocular Drug Delivery: Potential Uses for the Treatment of Diseases of the Posterior Segment and Beyond", Current Drug Metabolism, 4(3), pp. 213-222, 2003. https://doi.org/10.2174/1389200033489488

[9] Fox, S. I. "Sensory Physiology", In: Human Physiology, McGrawHill Education, Singapore, Singapore, 2016, pp. 266-315.

[10] Agarwal, P., Rupenthal, I. D. "In vitro and ex vivo corneal penetration and absorption models", Drug Delivery and Translational Research, 6(6), pp. 634-647, 2016. https://doi.org/10.1007/s13346-015-0275-6 and MR values and four basic physicochemical descriptors, $\mathrm{MW}, \operatorname{cog} P, \operatorname{cog} D_{74}$ and TPSA. Based on the results, we can conclude that although noticeable and obvious trends could be observed between the experimental corneal-PAMPA values $\left(\log P_{e}, \mathrm{MR}\right)$ and the lipophilicity and TPSA descriptors, the correlations with separate parameters alone were not strong enough for precise prediction of corneal permeability. To this avail, in the future in the possession of a larger experimental dataset of corneal-PAMPA values a thorough QSPR analysis may be carried out.

\section{Acknowledgement}

This research was funded by the New National Excellence Program of the Ministry of Human Capacities (grant number ÚNKP-19-2-I-BME-370).

[11] Lach, J. L., Huang, H. S., Schoenwald, R. D. "Corneal Penetration Behavior of $\beta$-Blocking Agents II: Assessment of Barrier Contributions", Journal of Pharmaceutical Sciences, 72(11), pp. 1272-1279, 1983.

https://doi.org/10.1002/jps.2600721109

[12] Prausnitz, M. R., Noonan, J. S. "Permeability of cornea, sclera, and conjunctiva: A literature analysis for drug delivery to the eye", Journal of Pharmaceutical Sciences, 87(12), pp. 1479-1488, 1998. https://doi.org/10.1021/js9802594

[13] Sunkara, G., Kompella, U. "Membrane Transport Processes in the Eye", In: Mitra, A. K. (ed.) Ophthalmic Drug Delivery Systems, Marcel Dekker, New York, NY, USA, 2003, pp. 13-58. https://doi.org/10.1201/9780203912072.ch2

[14] Dey, S. "Corneal cell culture models: a tool to study corneal drug absorption", Expert Opinion on Drug Metabolism \& Toxicology, 7(5), pp. 529-532, 2011. https://doi.org/10.1517/17425255.2011.570334

[15] Dargó, G., Vincze, A., Müller, J., Kiss, H. J., Nagy, Z. Z., Balogh, G. T. "Corneal-PAMPA: A novel, non-cell-based assay for prediction of corneal drug permeability", European Journal of Pharmaceutical Sciences, 128, pp. 232-239, 2019. https://doi.org/10.1016/j.ejps.2018.12.012

[16] Avdeef, A. "Permeability-PAMPA", In: Absorption and Drug Development: Solubility, Permeability, and Charge State, John Wiley \& Sons, Inc., Hoboken, NJ, USA, 2012, pp. 319-498. https://doi.org/10.1002/9781118286067.ch7

[17] Müller, J., Esső, K., Dargó, G., Könczöl, Á., Balogh, G. T. "Tuning the predictive capacity of the PAMPA-BBB model", European Journal of Pharmaceutical Sciences, 79, pp. 53-60, 2015. https://doi.org/10.1016/j.ejps.2015.08.019

[18] Sinkó, B., Garrigues, T. M., Balogh, G. T., Nagy, Z. K., Tsinman, O., Avdeef, A., Takács-Novák, K. "Skin-PAMPA: A new method for fast prediction of skin penetration", European Journal of Pharmaceutical Sciences, 45(5), pp. 698-707, 2012. https://doi.org/10.1016/j.ejps.2012.01.011 
[19] Lanevskij, K., Didziapetris, R. "Physicochemical QSAR Analysis of Passive Permeability Across Caco-2 Monolayers", Journal of Pharmaceutical Sciences, 108(1), pp. 78-86, 2019.

https://doi.org/10.1016/j.xphs.2018.10.006

[20] Hou, T. J., Zhang, W., Xia, K., Qiao, X. B., Xu, X. J. "ADME Evaluation in Drug Discovery. 5. Correlation of Caco-2 Permeation with Simple Molecular Properties", Journal of Chemical Information and Computer Sciences, 44(5), pp. 1585-1600, 2004. https://doi.org/10.1021/ci049884m

[21] Gozalbes, R., Jacewicz, M., Annand, R., Tsaioun, K., Pineda-Lucena, A. "QSAR-based permeability model for druglike compounds", Bioorganic \& Medicinal Chemistry, 19(8), pp. 2615-2624, 2011.

https://doi.org/10.1016/j.bmc.2011.03.011
[22] ChemAxon Ltd. "Marvin Calculator Plugins were used for structure property prediction and calculation (v. 19.19.0)", [computer program] ChemAxon Ltd., Available at: https://www.chemaxon.com/products/calculators-and-predictors [Accessed: 29 December 2019]

[23] GraphPad Software "GraphPad Prism version 7.03 for Windows was used", La Jolla California, USA, [computer program] Available at: https://www.graphpad.com/ [Accessed: 29 December 2019] 